\title{
ON THE GROUND: FIELD RESEARCH FROM AFGHANISTAN
}

\section{Travers BARCLAy CHILd}

Travers B. Child is affiliated with the Vrije Universiteit Amsterdam and the Tinbergen Institute, both in the Netherlands. He may be reached at t.b.child@vu.nl.

\section{Abstract}

This note introduces a four-article symposium on stability and reconstruction across Afghanistan. The contributors are experienced practitioners and/or field researchers drawn from a spectrum of the social sciences. Each of them has established a physical presence in Afghanistan for a significant period of time. Consequently, this symposium elucidates some critical aspects of the conflict and development phenomena which have thus far been overlooked.

$\mathrm{T}$ his symposium release incidentally marks the two-year anniversary of my own fieldwork in Afghanistan. After having conducted research on the relationship between reconstruction and conflict for a number of years, I felt compelled to visit Afghanistan myself to better understand the issues which impassioned me. Within twenty-four hours of walking the streets of Kabul and conversing with locals and expatriates, my perspective had undergone a drastic transformation. My theoretical priors were humbled as I discussed my research with Afghans and foreigners who lived the issues around which I had developed academic expertise from a distance. Later on I left the country feeling infinitely better acquainted with the topic of my research than when I had arrived. Yet at once I understood full well that my familiarity and intuition was far weaker than that of the experts I had left behind in Kabul.

As economists, our practical knowledge may forever be subordinate to that of our counterpart practitioners. After all, modern training in economics prioritizes mastery of research design and method over intimate familiarity with select topics. High theory and data-driven empirical work certainly have a role to play in the quest for knowledge surrounding the complex issues facing Afghanistan and other conflict-afflicted regions. But we should never forget to incorporate real-world considerations into such policy-relevant work. As academics, we tend to ignore each other across disciplines, even while developing parallel veins of literature. Moreover, we collectively ignore the discourse of practitioners and field experts who have devoted their careers to substantive, rather than methodological, matters.

This symposium seeks to help remedy the above ailments. In this spirit, I invited a group of cross-disciplinary practitioners and/or policy-oriented researchers to contribute to this collection. On account of professional engagement with their subject matter and personal experience in Afghanistan, these authors are extremely well versed in their respective areas of research. The articles herein thus offer valuable additions to our empirical and practical knowledge. None of these contributions would have been possible had the authors not established a physical presence in the country and embodied an honest and profound passion for their work.

Daniel Karell, from a sociological perspective, undertakes in-depth interviews with locals while immersed in Helmand province. From his field work new theoretical insights arise in regard to how reconstruction funding can reshuffle local power structures and produce unintended consequences of post-conflict reconstruction. Greg Adams draws on inside knowledge, gained through deployment with the U.S. military in Afghanistan, to shed new light on an ongoing empirical debate regarding the relative merits of "large" versus "small" reconstruction project funding. He uses unique military-grade data to assess the effectiveness of reconstruction spending at reducing violence. Jan Koehler, Kristóf Gosztonyi, Basir Feda, and Keith Child exploit part of an extremely rich database of quantitative and qualitative household-, village-, district-, and province-level data collected in Northeast Afghanistan. Adopting a mixed-methods approach, they explore the relationship between a development intervention and stability. They focus less on objective measures of development and stability than on local perceptions of these phenomena. Lastly, in Herat and Helmand provinces, James Weir and Hekmatullah Azamy conduct interviews with a broad swath of actors in the conflict, including Taliban fighters (former and present), government officials, and community leaders. The obtained testimonies offer a tangible grip on some economic drivers for insurgency (in the midst of a largely theoretical, academic debate). The authors argue that for stability to take hold, illicit funding practices must be stymied.

This symposium incorporates various disciplinary approaches and reflects a range of professional experiences 
across Afghanistan. This is true of the symposium as whole, but also of the coauthored work contained within. In addition to advancing knowledge for its own sake, we hope this symposium reminds readers of the diversity and flexibility of the social sciences. We hope it will inspire others to collaborate across disciplinary boundaries, as well as outside the academic sphere. By doing so, we can spark a broader dialogue around the substance of our research and, one hopes, influence policy accordingly. 